\title{
RELAÇÃO ENTRE A HIPERQUERATOSE DOS TETOS E A OCORRÊNCIA DE MASTITE SUB-CLÍNICA
}

\author{
Viviane Maia Araújo ${ }^{1}$, Adriano Henrique do Nascimento Rangel ${ }^{1}$, Henrique Rocha de \\ Medeiros $^{1}$, Inoque Deneri de Custódio Moutinho², Manuel Mateus Alexandre², Karla \\ Cavalcanti Bezerra'
}

\author{
1 UFRN \\ 2 Instituto Superior Politécnico do Kwanza Sul - ISPKS, Kwanza Sul, Angola. \\ Correspondência: Viviane Maia Araújo: vivi.maia@hotmail.com
}

\begin{abstract}
RESUMO: Objetivou-se avaliar os efeitos da hiperqueratose dos tetos sobre a mastite sub-clínica em vacas primíparas e pluríparas. Foram analisadas 51 vacas em lactação em rebanho na região agreste do estado do Rio Grande do Norte. Cada vaca foi primeiramente avaliada quanto ao escore de tetos, em seguida, realizou-se o escore da mastite sub-clínica, por meio do California Mastitis Test (CMT). Para os parâmetros hiperqueratose dos tetos e a mastite sub-clínica, foi realizada a análise de correlação de Pearson. A análise da variância e comparação de médias foi usada considerando-se o efeito da ordem de parto. A análise indicou uma correlação positiva entre os escores dos tetos e do CMT $(P \leq 0,001)$. Não houve efeito da ordem de parto sobre as médias do escore dos tetos, porém, para médias do escore do CMT, vacas primíparas apresentaram menores médias $(P \leq 0,001)$. O que indicou maior severidade da mastite sub-clínica em vacas pluríparas.
\end{abstract}

Palavras-chave: California Mastitis Test; contagem de células somáticas; escore dos tetos

\section{RELATIONSHIP BETWEEN TEAT-END CALLOSITY AND OCCURRENCE OF SUBCLINICAL MASTITIS}

\begin{abstract}
The objective was to evaluate the effects of teat-end callosity on subclinical mastitis in cows primiparous and pluriparous. Were analyzed 51 dairy cows in the herd in the region agreste in the state of Rio Grande do Norte. Each cow was first evaluated in the score teat-end, then held the score of subclinical mastitis, using the California Mastitis Test (CMT). For the parameters of teat-end callosity ceilings and subclinical mastitis was performed Pearson correlation analysis. The analysis of variance and mean comparison was used considering the effect of parity. The analysis indicated a positive correlation between the scores of the teats and CMT $(P \leq 0.001)$. There was no effect of parity on the mean score of the teats, but for the average CMT score, primiparous cows had lower mean $(P \leq 0.001)$. What indicated greater severity of subclinical mastitis in pluriparous cows.
\end{abstract}

Key Words: California Mastitis Test; somatic cell count; teat score 


\section{INTRODUÇÃO}

Apesar do desenvolvimento de diversas estratégias de controle e prevenção, a mastite continua sendo a doença que mais causa prejuízos à indústria leiteira. $\mathrm{O}$ monitoramento da mastite sub-clínica pode ser feito por testes auxiliares, entre os quais a determinação da contagem de células somáticas (CCS), individual das vacas e do tanque, é um dos mais importantes (Santos e Fonseca, 2007). O Califórnia Mastitis Test (CMT) é um teste auxiliar indireto, que estima a CCS de cada teto, e tem sido muito usado por ser uma ferramenta prática e viável no controle da doença (Langoni et al., 2006; Zegarra et al., 2007).

A principal forma de transmissão dos agentes causadores de mastite é a penetração através do orifício do teto. Tetos lesionados são mais susceptíveis à colonização de microrganismos patogênicos (Rasmussen e Lasen, 1998). Alguns fatores podem prejudicar a integridade dos tetos, sendo possível classificá-los em infecciosos (vírus, bactérias e fungos) e não infecciosos (ordenha, ambiente e anatomo-fisiologia da vaca) (Neijenhuis et al., 2001). A hiperqueratose trata-se de uma resposta fisiológica normal da pele dos tetos em relação aos fatores agressores, e essas alterações podem acontecer de forma súbita, ou á longo prazo (Santos e Fonseca, 2007). A ocorrência de hiperqueratose nos rebanhos permite maior oportunidade para entrada dos microrganismos no canal do teto, o que influencia adversamente na qualidade do leite e sanidade do úbere (Hillerton et al., 2001).

A gravidade da hiperqueratose nos tetos pode ser avaliada visualmente por meio de quatro tipos de escores, que propõe: $N$ (sem formação de anel na extremidade do teto); S (leve formação de anel na extremidade do teto); $\mathrm{R}$ (formação de anel rugoso na extremidade do teto); e VR (intensa formação de anel rugoso na extremidade do teto). Recomenda-se que sejam verificadas tanto as laterais quanto as extremidades dos tetos, e que sejam avaliadas $20 \%$ das vacas em rebanhos maiores de maneira aleatória; em pequenos rebanhos o ideal é que todas as vacas sejam examinadas. $O$ padrão para o sistema de escores de tetos mais usado é o preconizado pelo "The Teat Club International", recomendam que menos de $20 \%$ do rebanho apresente escores para lesões mais graves (Kirk, 2003). Rebanhos com percentuais acima dessa recomendação necessitam de uma avaliação detalhada do equipamento e do manejo de ordenha (Santos e Fonseca, 2007). Segundo Burmeiser et al. (1995) a avaliação das condições dos tetos é uma ferramenta de manejo útil para o monitoramento e tomada de decisões para novas estratégias na prevenção da mastite.

Na região agreste do Rio Grande do Norte, há uma grande dificuldade no pós venda e manutenções dos equipamentos de ordenha. Existe a constatação da ocorrência da hiperqueratose dos tetos, no entanto, a avaliação das condições dos tetos, apesar de simples não é uma ferramenta difundida entre os produtores de leite.

Diante do exposto, objetivou-se verificar a associação entre a presença da hiperqueratose dos tetos sobre a mastite sub-clínica em vacas primíparas e pluríparas em rebanho leiteiro na região agreste no estado do Rio Grande do Norte.

\section{MATERIAL E MÉTODOS}

O estudo foi conduzido em fevereiro de 2011 na propriedade Sítio Novo, localizada no município de Macaíba, região agreste do estado do Rio Grande do Norte. A composição 
racial do rebanho é constituída de vacas mestiças (holandês x gir leiteiro). Havia uma média de 128 vacas em lactação no mês em que o estudo foi conduzido, ordenhadas duas vezes ao dia, em equipamento de ordenha mecânica tipo espinha de peixe com oito conjuntos. O manejo de ordenha adotado contemplava o uso dos pré e pós dipping, uso de papel toalha descartável na secagem dos tetos, além do teste da caneca telada. Os animais eram tratados com antibióticos no período seco. O California Mastitis Test e análise eletrônica do leite do tanque de resfriamento eram realizados mensalmente.

A classificação dos escores da hiperqueratose dos tetos e escore da mastite sub-clínica foi conduzida em 51 vacas divididas em 14 primíparas e 37 pluríparas para ordem de parto, em uma única avaliação, foram selecionadas aleatoriamente durante a primeira ordenha do dia, totalizando 203 tetos, conforme recomendação do "The Teat Club International" (Kirk,2003), em que $20 \%$ das vacas sejam avaliadas para grandes rebanhos, para essa pesquisa foram avaliadas $39,84 \%$ do total de vacas do rebanho.

Cada vaca foi primeiramente avaliada quanto aos escores de tetos, $(\mathrm{N}) ; \quad(\mathrm{S}) ; \quad(\mathrm{R})$ e (VR) para isso, empregou-se a metodologia preconizada pelo "The Teat Club International" (Kirk, 2003), Avaliou-se por meio de modelo adaptado substituindo os escores de tetos pelos números 1, 2, 3 e 4 respectivamente, e ainda, respectivas figuras das lesões dos tetos com vista lateral e de extremidade.

Em seguida, realizou-se o escore da mastite sub-clínica, por meio do Califórnia Mastitis Test (CMT), segundo Philpot e Nickerson, 1991.

Realizou-se uma análise descritiva dos dados considerando a gravidade das lesões do rebanho, pelo procedimento MEANS (SAS, 1999). Para os parâmetros hiperqueratose e a mastite sub-clínica, considerando tetos, foi realizada a análise de correlação de Pearson pelo procedimento CORR (SAS, 1999). A análise da variância foi realizada considerando-se o efeito da ordem de parto. As médias dos tetos foram comparadas pelo teste de Tukey a $1 \%$ de probabilidade nas interações (escore do teto $x$ escore do CMT) usando o procedimento GLM (SAS, 1999).

\section{RESULTADOS E DISCUSSÃO}

Do total de 51 vacas avaliadas, $13,7 \%$ apresentaram escores 3 e 4 e apenas uma vaca $(0,49 \%)$ apresentou escore 4 para hiperqueratose. A literatura recomenda que esse percentual para animais no rebanho, seja menor que $20 \%$ e $10 \%$, respectivamente (Kirk, 2003; Santos e Fonseca, 2007).

Dos tetos avaliados quanto aos escores para hiperqueratose, $8,86 \%$ foram classificados nos escores 3 e 4 , enquanto $0,49 \%$ apresentou lesão de maior gravidade (escore 4) (Figura 1). Portanto, os resultados demonstram que a propriedade estudada apresentava rebanho com baixa ocorrência de hiperqueratose nos tetos, sendo necessária apenas intensificação nas ações preventivas, para que tetos com escore 2 não evoluam na gravidade da lesão, pois apresentam-se em percentual elevado (Figura 1).

A análise de correlação indicou, ainda, uma associação fraca e positiva $(P \leq 0,001)$ entre os escores dos tetos e do California Mastitis Test (CMT), apenas $22 \%$ da variância do escore do CMT pode ser explicada pelo escore dos tetos. O que pode ser atribuído ao tamanho da amostragem do presente estudo. Dos 98 tetos lesionados, 65 apresentaram resultado positivo para 0 teste CMT, ou seja, dos tetos que 
apresentaram alguma lesão para hiperqueratose, a chance de ter o CMT positivo foi de apenas 1,96. Em trabalho semelhante, Lewis et al. (2000), também encontraram correlação significativa entre a ocorrência de mastite sub-clínica e lesões de esfíncter dos tetos. Segundo Mulei (1999), os quartos mamários com lesões de tetos apresentaram 7,2 vezes mais probabilidade de apresentarem-se positivos no teste CMT.

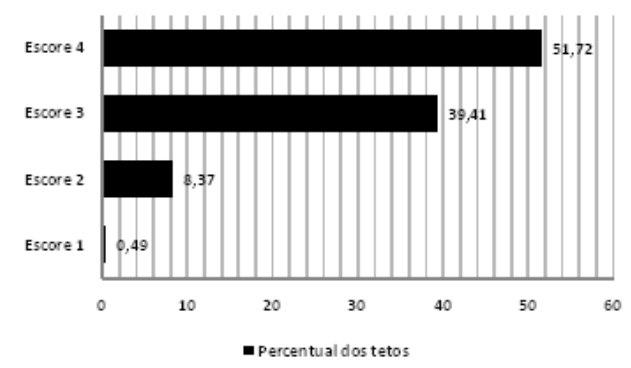

Figura 1 - Distribuição percentual dos tetos analisados de acordo com o escore de le são da hiperqueratose em uma propriedade leiteira de Macaiba (RN). Escore 1 (sem formação de anel na extremidade do teto); Escore 2 (leve formação de anel na extremidade do teto); Escore 3 (formação de anel rugoso na extremidade do teto); Escore 4 (intensa formação de anel rugoso na extremidade do teto).

Manter a extremidade dos tetos em boas condições é extremamente importante, pois nessa região, a musculatura do esfíncter desempenha um papel fundamental na contração do canal do teto mantendo-o fechado entre as ordenhas, o que impede a entrada de patógenos no interior da glândula mamária. Essa ação é auxiliada por células maduras de queratina, presentes no canal do teto e juntos representam a barreira primária na resistência às mastites (Santos e Fonseca, 2007). Fato este, comprovado por Zecconi et al. (1996), que encontraram um significativo aumento de novas infecções intramamárias, com 0 incremento de $5 \%$ na espessura das extremidades dos tetos. Com isso, comprova-se que a hiperqueratose é um fator de risco para a ocorrência da mastite sub-clínica.

Como a hiperqueratose é uma alteração normal da pele dos tetos que ocorre em longo prazo, devido a fatores ligados, principalmente, a ordenha (Neijenhuis et al., 2001). À medida que a vaca contribui em sua vida produtiva, torna-se mais vulnerável a adquirir tais alterações, no entanto, considerando a ordem do parto, a análise não indicou diferença de médias significativas para o escore dos tetos entre vacas primíparas e pluríparas (Tabela 1).

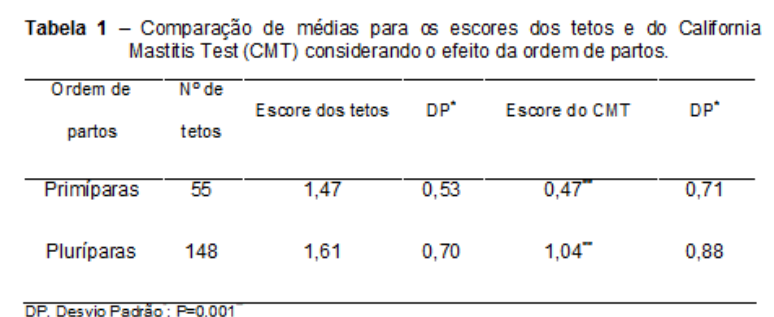

Em contrapartida, o escore do teste CMT apresentou média significativamente maior para vacas pluríparas (Tabela 1), mas isso pode estar associado a outros fatores não mensurados nessa pesquisa, já que o aumento da contagem de células somáticas é multifatorial. Leavens et al. (1997) também reportaram que o efeito da ordem de parto influenciava no aumento da CCS nos animais. Assim como, Souza et al. (2009), que relataram o incremento da CCS com o avanço da idade. Isso se deve ao fato, do contágio da mastite sub-clínica estar relacionado a fatores ligados a rotina de ordenha. Em vacas primíparas as oportunidades de contaminação e colonização dos tetos por parte dos microrganismos são mais reduzidas do que em vacas pluríparas pelo próprio tempo de exposição aos fatores de risco.

O que se observou nesse estudo é que, mesmo apresentando 48,27\% dos tetos acometidos com hiperqueratose (Figura 1), o mesmo não está associado ao incremento da contagem de células somáticas, isso pode ser explicado pelo criterioso manejo de ordenha adotado na propriedade. No entanto, sugere-se o uso dessa ferramenta em outros sistemas de produção, uma vez que os resultados são peculiares. 


\section{CONCLUSÃO}

A hiperqueratose dos tetos em vacas leiteiras apresentou fraca correlação ao escore da contagem de células somáticas pelo Califórnia Mastitis Test e não sofreu alteração com a ordem de parto, apesar do incremento da contagem de células somáticas serem maiores em vacas pluríparas.

\section{REFERÊNCIAS}

BURMEISTER, J.E.; FOX, L.K.; HANCOCK, D.D. et al. Survey of dairy managers in the pacific northwest identifying factors associated with teat chapping. Journal of Dairy Science, v.78, n. 9, p. 2073-2082, 1995.

HILLERTON, J.E.; MEIN, G.A.; NEIJENHUIS, F. et al. Evaluation of bovine teat condition in commercial dairy herds: infectious factors and infections. In:International Symposium on Mastitis and Milk Quality, 2001, Vancouver, BC, Canada. Proceedings...Vancouver: AABPNMC, 2001. p.347-351.

KIRK, J.H. [2003]. A System for scoring teat end condition. Disponível em:

$<$ http://www.pdfbe.com/te/teat-canal-book3.pdf>. Acesso em: 12/02/2011.

LANGONI, H.; DOMINGUES, P.F.; BALDINI, S. Mastite caprina: seus agentes e sensibilidade frente a antimicrobianos. Revista Brasileira de Ciência Veterinária, v.13, n.1, p.51-54, 2006.

LEAVENS, H.; DELUYKER, H.; SCHUKKEN, Y.H. et al. Influence of parity and stage of lactation on the somatic cell count in bacteriologically negative dairy cows. Journal of Dairy Science, v.80, n.12, p.3219-3226, 1997.

LEWIS, S.; COCKCROFT, P. D.; BRAMLEY, R. A. et al. The likelihood of subclinical mastitis in quarters with different types of teat lesions in the dairy cow. Cattle Practice, v.8, n.3, p.293-299, 2000.

MULEI, C. M. Teat lesions and their relationship to intramammary infections on small-scale dairy farms in Kiambu district in Kenya. Journal of the South African Veterinary Association, v.70, n.4, p.156-157, 1999.

NEIJENHUIS, F.; MEIN, G.A.; MORGAN, W.F. et al. Relationship between teat-end callosity or hyperkeratosis and mastitis. In: International Symposium on Mastitis and Milk Quality, 2001, Vancouver, BC, Canada.

Proceedings...Vancouver: AABP-NMC, 2001. p.365-366.

PHILPOT, W.N.; NICKERSON, S.C. Mastitis: counter attack. Naperville: IL. Babson Bros. Co, 1991. 150p.

RASMUSSEN, M.D.; LARSEN, H.D. The effect of post milking teat dip and suckling on teat skin condition, bacterial colonization, and udder health. Acta Veterinaria Scandinavica, v.39, n.4, p.443-452, 1998.

SANTOS, M.V.; FONSECA, L.F.L. Estratégias para controle de mastite e melhoria da qualidade do leite. Barueri: SP. Manole, 2007. $314 p$.

SOUZA, G.N.; BRITO, J.R.F.; MOREIRA, E.C. et al. Variação da contagem de células somáticas em vacas leiteiras de acordo com patógenos da mastite. Arquivo Brasileiro de Medicina Veterinaria e Zootecnia, v.61, n.5, p.1015-1020, 2009.

STATISTICAL ANALYSIS SYSTEM - SAS. SAS/STAT: user's guide, version 9.1. Cary: 1999. 448p.

ZECCONI, A.; BRONZO, V.; PICCININI, R. Field study on the relationship between teat thickness changes and intramammary infections. Journal of Dairy Research, v.63, n.3, p.361-368, 1996.

ZEGARRA, J.J.Q.; OLIVEIRA, B.C.R.S.; SILVA, R.A. et al. Aspectos da produção leiteira em pequenas unidades de produção familiar no assentamento Mutirão Eldorado em Seropédica, Rio de Janeiro. Revista Brasileira de Ciência Veterinária, v.14, n.1, p.12-18, 2007. 